\title{
Combination Effects of Hispidin and Gemcitabine via Inhibition of Stemness in Pancreatic Cancer Stem Cells
}

\author{
NISANSALA CHANDIMALI ${ }^{1}$, DO LUONG HUYNH ${ }^{1}$, WOO YONG JIN ${ }^{2}$ and TAEHO KWON ${ }^{1,2,3}$ \\ ${ }^{1}$ Laboratory of Animal Genetic Engineering and Stem Cell Biology, \\ Advanced Convergence Technology and Science, Jeju National University, Jeju, Republic of Korea; \\ ${ }^{2}$ Research and Education (R\&E) 2017, Jeju Science High School, Jeju, Republic of Korea; \\ ${ }^{3}$ Laboratory of Animal Genetic Engineering and Stem Cell Biology, \\ Subtropical/Tropical Organism Gene Bank, Jeju National University, Jeju, Republic of Korea
}

\begin{abstract}
Background/Aim: Natural products extracted from plants can be potent for developing pharmaceutical products. Hispidin, a polyphenolic compound mainly derived from the medicinal mushroom Phellinus linteus, has been shown to have a therapeutic potential against cancer cells. Pancreatic cancer is one of the most aggressive solid malignancies with high resistance to existing drugs. Cancer stem cells (CSCs) are responsible for chemoresistance. The present study aimed to evaluate the anticancer effects of hispidin on pancreatic CSCs. Materials and Methods: The cytotoxic effects of hispidin on $B x P C-3$ and AsPC-1 pancreatic cancer cells and BxPC-3 $C D 44^{+}$CSCs and the synergistic effects of gemcitabine and hispidin on CSCs were evaluated by a series of in vitro experiments including the 3-(4,5-dimethythiazol-2-yl)-2,5diphenyl tetrazolium bromide (MTT), fluorescence-activated cell sorting, colony forming, Transwell assay, immunocytochemistry, sphere-forming, and western blot assays. Results: Hispidin exerted antitumor effects against both BxPC-3 pancreatic cancer cells and CSCs. Furthermore, it was found that hispidin sensitized pancreatic CSCs to gemcitabine and promoted the therapeutic efficacy of gemcitabine. Conclusion: Hispidin might be a novel chemosensitizer for gemcitabine and a potential synergistic agent for increasing the therapeutic index of gemcitabine as a treatment for pancreatic cancer.
\end{abstract}

Correspondence to: Taeho Kwon, Ph.D., Laboratory of Animal Genetic Engineering and Stem Cell Biology, Subtropical/Tropical Organism Gene Bank, Jeju National University, 102, Jejudaehakro, Jeju-si, Jeju, 63243, Republic of Korea. Tel: +82 647548275 , Fax: +82 647252403, e-mail: taehokwonk@gmail.com and Woo Yong Jin, B.S., Research and Education (R\&E) 2017, Jeju Science High School, 421-1, Sallokbuk-ro, Jeju-si, Jeju, 63144, Republic of Korea. Tel: +82 647540705, Fax: +82 647540777, e-mail: rebertyangel@naver.com

Key Words: Hispidin, pancreatic cancer, NF-kB, cancer stem cells, gemcitabine.
Pancreatic cancer is one of the deadliest malignancies; it is currently the fourth leading cause of cancer-related deaths, with a median survival period of 5-8 months. It is assumed that pancreatic cancer will be the second leading cause of cancer-related deaths by 2030 (1). Only around 5\% of patients with pancreatic cancer survive for more than 5 years after initial diagnosis (2). The mortality rate associated with pancreatic cancer is almost equal to its incidence rate because of late diagnosis and poor prognosis. The poor prognosis is attributable to early metastasis in pancreatic cancer development, a strong migratory nature, late presentation due to the difficulties associated with the initial diagnosis, and unresponsiveness to most conventional cancer therapies (3, 4). Pancreatic cancer stem cells (CSCs) sustain tumor formation, metastasis, and chemoresistance of pancreatic cancer. Conventional chemotherapy and radiotherapy only affect rapidly growing cancer cells and fail to eliminate CSCs (5). Recently, CD44, an adhesion molecule expressed on the surface of CSCs, was found to play a role in determining the characteristics of pancreatic CSCs and act as a master regulator of CSCs $(6,7)$. Therefore, in this study, we focused on $\mathrm{CD}_{4} 4^{+}$pancreatic cancer cells because improved new strategies are needed to target CSCs.

Surgery is not beneficial for the majority of patients with pancreatic cancer because only $15-20 \%$ of pancreatic tumors are local and therefore anatomically resectable upon diagnosis. Furthermore, even after surgical resection, the resulting prognosis is very poor due to the high rate of metastasis. Therefore, chemotherapeutic drugs are frequently needed, although the response rates to conventional drugs have been reported to be lower than $25 \%(3,8)$. Gemcitabine plays a major role in chemotherapy for pancreatic cancer as the first-line chemotherapeutic drug, by regulating stemness and chemoresistance via phosphorylation of multiple proteins and signaling pathways such as the nicotinamide adenine dinucleotide phosphate-oxidase (NOX)/reactive oxygen species (ROS)/nuclear factor-kappa B (NF-кB)/signal 
transducer and activator of transcription 3 (STAT3) pathway (9). However, the reduced therapeutic efficacy of certain doses of gemcitabine because of intrinsic and acquired resistance of pancreatic cancer cells remains a major challenge, and there is an urgent need for diagnostic and treatment strategies to increase tumor sensitivity to gemcitabine (10). Recent studies have suggested that combination therapy with a targeted medicine that inhibits $\mathrm{NF}-\mathrm{kB}$ activity increases the sensitivity of pancreatic cancer cells to gemcitabine, as the activation of NF- $\mathrm{kB}$ is associated with pancreatic cancer progression via up-regulation of cell proliferation, chemoresistance, invasion, angiogenesis, metastasis, and suppression of apoptosis $(11,12)$. However, the results from studies thus far have been inadequate and new approaches are needed to maximize the effectiveness of gemcitabine.

Hispidin is a polyphenolic compound, mainly derived from a valuable medicinal mushroom, Phellinus linteus (Figure 1A); it is well known for its strong anticancer, antioxidant, and DNA-damage protection activities. Studies have already reported the ability of hispidin to inhibit tumor growth and metastasis (13). Hispidin has also been reported to inhibit the transcriptional activity of NF-kB (14, 15). Furthermore, according to some recent studies, hispidin is cytotoxic against human lung, squamous, liver, and pancreatic cancers (16). Moreover, previous studies have revealed that hispidin inhibits cell viability and mediates apoptotic signals in CSCs by generating reactive oxygen species (17).

In the present study, we explored the unique anticancer activity of hispidin and its activity as a chemosensitizer of gemcitabine in malignant pancreatic cancer. Even though previous studies have shown the anticancer activity of hispidin against diverse types of cancer cells, to our knowledge, this is the first study to show the cytotoxic activity of hispidin in CSCs and show the effective and promising synergistic therapeutic effect of hispidin used in combination with gemcitabine in pancreatic cancer cells.

\section{Materials and Methods}

Reagent. Hispidin [6-(3,4-dihydroxystyryl)-4-hydroxy-2-pyrone; solid, $\geq 98 \%$ of purity by high-performance liquid chromatography, derived from $P$. linteus was purchased from the National Development Institute of Korean Medicine (NIKOM) (http:// www.nikom.or.kr/eng/main.jsp), Gyeongsan, Republic of Korea.

Cell culture and treatments. BxPC-3 and AsPC1 human pancreatic cancer cell lines were obtained from the American Type Culture Collection (ATCC, Manassas, VA, USA). Human pancreatic cancer cell lines BxPC-3 and AsPC1 were maintained in Dulbecco's modified Eagle's medium (DMEM) (Invitrogen, Carlsbad, CA, USA) with $10 \%$ fetal bovine serum (FBS; Welgene, Gyeongsan, Gyeongsangbuk-do, South Korea) and $1 \%$ penicillin $(100 \mathrm{U} / \mathrm{ml})$ and streptomycin $(100 \mathrm{mg} / \mathrm{ml})$. BxPC-3 CD44+ cells (CSCs) were cultured in the above complete media supplemented with $10 \mathrm{ng} / \mathrm{ml}$ human epidermal growth factor (hEGF) (Sigma Aldrich, St. Louis, MO, USA) and $20 \mathrm{ng} / \mathrm{ml}$ basic fibroblast growth factor (bFGF).

Transwell migration and Matrigel invasion. In vitro migration and invasion assays were performed using Transwell 24-well chambers with $8.0-\mu \mathrm{M}$ pore polycarbonate membranes (Merck Millipore, Darmstadt, Germany) without (migration) or with (invasion) Matrigel. Briefly, $200 \mu \mathrm{l}$ of BxPC-3 CD $44^{+}$cell suspensions treated with or without $150 \mu \mathrm{M}$ of hispidin in $0.5 \%$ FBS-containing medium were added separately to the upper chambers $\left(1 \times 10^{5}\right.$ cells/chamber). The bottom chamber was filled with $800 \mu \mathrm{I}$ of the medium supplemented with $20 \%$ FBS as a chemoattractant. Cells were then incubated for $24 \mathrm{~h}$ at $37^{\circ} \mathrm{C}$ and $5 \% \mathrm{CO}_{2}$. Cells which passed through the coated membrane to the lower surface were then fixed with $4 \%$ paraformaldehyde and stained with $0.1 \%$ crystal violet for $1 \mathrm{~h}$. Images were then captured using a microscope.

Immunocytochemistry. $\mathrm{BxPC}-3 \mathrm{CD} 44^{+}$cells treated with or without hispidin or gemcitabine were fixed with $3.7 \%$ formaldehyde in $1 \times$ phosphate-buffered saline (PBS) for $10 \mathrm{~min}$ at room temperature. They were then blocked with $1 \times$ PBS containing $0.5 \%$ Triton X-100 and $1 \%$ bovine serum for $60 \mathrm{~min}$ at room temperature and incubated with primary antibodies to homing cell adhesion molecule (HCAM) (DF1485), NANOG (1E6C4), Sex-determining region Y)-box 2 (SOX2) (E-4), (Santa Cruz Biotechnology) for $18 \mathrm{~h}$. On the following day, the cells were washed with $1 \times$ PBS with Tween 20 and incubated with secondary antibodies, goat anti-rabbit immunoglobulin (Ig)G (Alexa Fluor 488; Abcam, Cambridge, MA) and goat anti-mouse IgG-PE (Santa Cruz Biotechnology, Dallas, TX, USA) respectively for $2 \mathrm{~h}$ at room temperature. Nuclei were visualized by 4',6-diamidino-2-phenylindole (DAPI) staining. Images were acquired and observed qualitatively after $20 \mathrm{~min}$ of DAPI staining using a microscope.

Sphere-formation assay. Pancreatic CSCs treated with $150 \mu \mathrm{M}$ of hispidin for $48 \mathrm{~h}$ and non-treated CSCs $\left(2 \times 10^{3}\right)$ were seeded in 2 $\mathrm{ml}$ of cell culture medium [serum-free DMEM/F12 (Gibco, Grand Island, NY, USA)] containing B27 supplement (1:50; Invitrogen), $20 \mathrm{ng} / \mathrm{ml}$ EGF (Calbiochem), and $0.5 \%$ bovine serum albumin (Sigma Aldrich) per well in a 6-well ultra-low cluster plate (Corning Inc, Corning, NY, USA). The spheres were obtained after 7 days by using an inverted microscope. Spheres were fixed for $30 \mathrm{~min}$ with $30.03 \mathrm{~g} / \mathrm{mol}$ formaldehyde solution. Cells were then rinsed twice with PBS and incubated in blocking solution consisting of $1 \times$ PBS containing $0.5 \%$ Triton $\mathrm{X}-100$ and $1 \%$ bovine serum for $1 \mathrm{~h}$. Cells were allowed to incubate overnight at $37^{\circ} \mathrm{C}$ with primary antibody solution consisting $0.1 \%$ Triton-X100, $10 \% \mathrm{NaNO}_{3}$ and $1 \times \mathrm{PBS}$. Cells were rinsed twice in $1 \times$ PBS prior to incubating with secondary antibody for $2 \mathrm{~h}$ in the dark place at room temperature. Cells were then rinsed twice with $1 \times$ PBS and counterstained with DAPI diluted in $1 \times$ PBS for $20 \mathrm{~min}$ prior to visualization and image capturing using microscope.

Western blotting. Lysates from hispidin and gemcitabine-treated or untreated BxPC-3 and BxPC-3 CD44+ cells were collected in NP40 lysis buffer ( $150 \mathrm{mM} \mathrm{NaCl}, 1 \%$ Nonidet p-40, $50 \mathrm{mM}$ Tris, $\mathrm{pH}$ 8.0 , and a protease inhibitor cocktail). Equal amounts of proteins from each cell lysate were resolved by sodium dodecyl sulfate polyacrylamide gel electrophoresis. Thereafter, the proteins were transferred to nitrocellulose membranes (BIO-RAD, Hercules, CA, 
USA), which were blocked with $10 \%$ skim milk and $0.1 \%$ Tween 20 in Tris-buffered saline for $1 \mathrm{~h}$ at room temperature. Primary antibodies [against CD44, NF-kB, p53, B-cell lymphoma 2 (BCL2), cleaved caspase-3, cleaved poly (ADP-ribose) polymerase (PARP), NANOG, and SOX2 were added overnight at $4{ }^{\circ} \mathrm{C}$, followed by incubation with a secondary antibody at room temperature for $4 \mathrm{~h}$. Antibody expression levels were checked qualitatively against glyceraldehyde 3-phosphate dehydrogenase (GAPDH) which was used as the control and obtained from AbFrontier Technology (Seoul, South Korea).

Colony-formation assay. BxPC- $3 \mathrm{CD} 44^{+}$cells $\left(1 \times 10^{3}\right.$ cells/well $)$ were plated in 6-well plates and maintained in an incubator at $37^{\circ} \mathrm{C}$ with $5 \% \mathrm{CO}_{2}$ for 7 days. The cells were then washed with $1 \times \mathrm{PBS}$, fixed with $3.7 \%$ formaldehyde for $10 \mathrm{~min}$, treated with methanol for $20 \mathrm{~min}$, and stained with crystal violet for $30 \mathrm{~min}$. The plates were washed three times with $1 \times$ PBS prior image capturing by using a camera.

Annexin $V$ staining. BxPC-3 CD44+ cells treated withor without hispidin for $48 \mathrm{~h}$ were washed with $1 \times \mathrm{PBS}$, stained with annexin $\mathrm{V}$ binding buffer (BD Biosciences, San Diego, CA, USA) and labeled with fluorescein isothiocyanate-conjugated Annexin $\mathrm{V}$ according to the manufacturer's protocol. Cells were sorted on a FACSCalibur flow cytometer (BD Biosciences, San Jose, CA, USA).

2',7'-Dichlorodihydrofluorescein diacetate (DCF-DA) assay. The reactive oxygen species (ROS) in $\mathrm{BxPC}-3 \mathrm{CD} 44^{+}$cells with and without 50,100 and $150 \mu \mathrm{M}$ of hispidin treatment were determined using DCFDA (Invitrogen). Cells were incubated with $20 \mathrm{mM}$ of DCF-DA for 15 min at $37^{\circ} \mathrm{C}$ and then washed with $1 \times$ PBS. DCF-DA\% was analyzed on a FACSCalibur flow cytometer (BD Biosciences).

Data analysis. Statistical analyses were conducted using SPSS v.20.0.1 software (SPSS Inc., Chicago, IL, USA). The chi-square test or Fisher's exact test was used as appropriate. Differences with values of $p<0.05$ were considered statistically significant.

\section{Results}

Hispidin significantly down-regulates cell proliferation and stemness of BxPC-3 and AsPC1 pancreatic cancer cells. To confirm the cytotoxic effects of hispidin, we initially assessed the antiproliferative effect of hispidin on AsPC1 and BxPC-3 pancreatic cancer cells in a dose-dependent manner. As shown in Figure 1B, the MTT assay revealed that hispidin reduced the growth of the pancreatic cancer cells. As hispidin was more effective against $\mathrm{BxPC}-3$ cells than AsPC 1 cells, BxPC-3 cells were selected to further study the cytotoxic effects of hispidin on pancreatic cancer cells.

To determine the mechanisms underlying the cytotoxic effects of hispidin, the expression of $\mathrm{p} 53, \mathrm{NF}-\mathrm{kB}$, apoptosisrelated proteins, CSC marker CD44, and stemness genes in cells treated with 50,100 and $150 \mu \mathrm{M}$ of hispidin for $48 \mathrm{~h}$ as determined by western blotting was compared with that of non-treated cells. Interestingly, the expression of tumorsuppressor p53, cleaved caspase-3, and cleaved PARP was up-regulated with increasing concentration of hispidin, while the expression of $\mathrm{NF}-\mathrm{kB}$ and BCL2 was down-regulated
(Figure 1C). Furthermore, western blotting showed that hispidin down-regulated the expression of stemness markers NANOG and SOX2 and the CSC marker CD44 in a dosedependent manner (Figure 1C). These results together suggest that hispidin suppresses cell stemness, NF-kB activation, and proliferation of pancreatic cancer cells, thereby inducing apoptosis.

Hispidin-induced apoptosis attenuates the proliferation of BxPC-3 CD $44^{+}$pancreatic CSCs. To further investigate the role of hispidin as an anticancer agent, its effects on pancreatic CSCs was assessed. Firstly BxPC-3 CD $44^{+}$ pancreatic CSCs were separated as a subpopulation of cells from BxPC-3 cells. The proportion of CD $44^{+}$BxPC- 3 cells was $90 \%$. The effects of hispidin on cell viability, apoptotic cell population, and cell-cycle stages of CSCs were then analyzed. In response to hispidin treatment for $24 \mathrm{~h}$, the cell viability of $\mathrm{BxPC}-3 \mathrm{CD}_{4} 4^{+}$cell decreased in a dosedependent manner. Continuous treatment with the same concentration of hispidin for a longer period ( $48 \mathrm{~h}$ ) increased the effect of hispidin. Interestingly, the reduction in cell viability in response to hispidin treatment for $72 \mathrm{~h}$ was similar to that after $48 \mathrm{~h}$ (Figure $2 \mathrm{~A}$ and B). Furthermore, the MTT assay showed that $150 \mu \mathrm{M}$ hispidin was sufficient to suppress the proliferation of pancreatic CSCs after treatment for $48 \mathrm{~h}$ (Figure 2C).

Apoptosis has been implicated as one of the mechanisms by which hispidin inhibits cell proliferation (17). Increased apoptotic cell populations were observed with increasing concentrations of hispidin treatment for $48 \mathrm{~h}$. Intriguingly, FACS analysis with Annexin V staining and DCF-DA assay revealed that $150 \mu \mathrm{M}$ hispidin treatment for $48 \mathrm{~h}$ was sufficient to induce pancreatic CSC apoptosis, thereby suppressing cell proliferation (Figure 2D and E). The cellcycle profile of cells treated with $150 \mu \mathrm{M}$ hispidin for $48 \mathrm{~h}$ was also examined and it was found that the number of $\mathrm{S}$ phase cells was reduced with an increase in the number of $G_{1}$ phase cells and reduction in the number of $G_{2}$ phase cells (Figure 2F). These findings suggested that the reduction of BxPC-3 CSC proliferation likely resulted from hispidininduced $\mathrm{G}_{1}$ arrest and cell apoptosis, and it clearly suggested that hispidin exerts cytotoxic effects on pancreatic CSCs.

Hispidin reduces the stemness, migration, and self-renewal ability of $\mathrm{CD}_{4} 4^{+} \mathrm{BxPC}-3$ pancreatic $C S C s$. To better understand the cytotoxic effects of hispidin on cancer stemlike properties of pancreatic CSCs, more detailed in vitro analyses were performed in $\mathrm{CD}_{4} 4^{+} \mathrm{BxPC}-3$ cells treated with $150 \mu \mathrm{M}$ hispidin for $48 \mathrm{~h}$. A colony-formation assay showed that hispidin treatment significantly reduced the numbers of $\mathrm{BxPC}-3 \mathrm{CD}_{4} 4^{+}$colonies, indicating the inhibition of cell proliferation by hispidin treatment (Figure 3A). A transwell assay with Matrigel and without Matrigel 

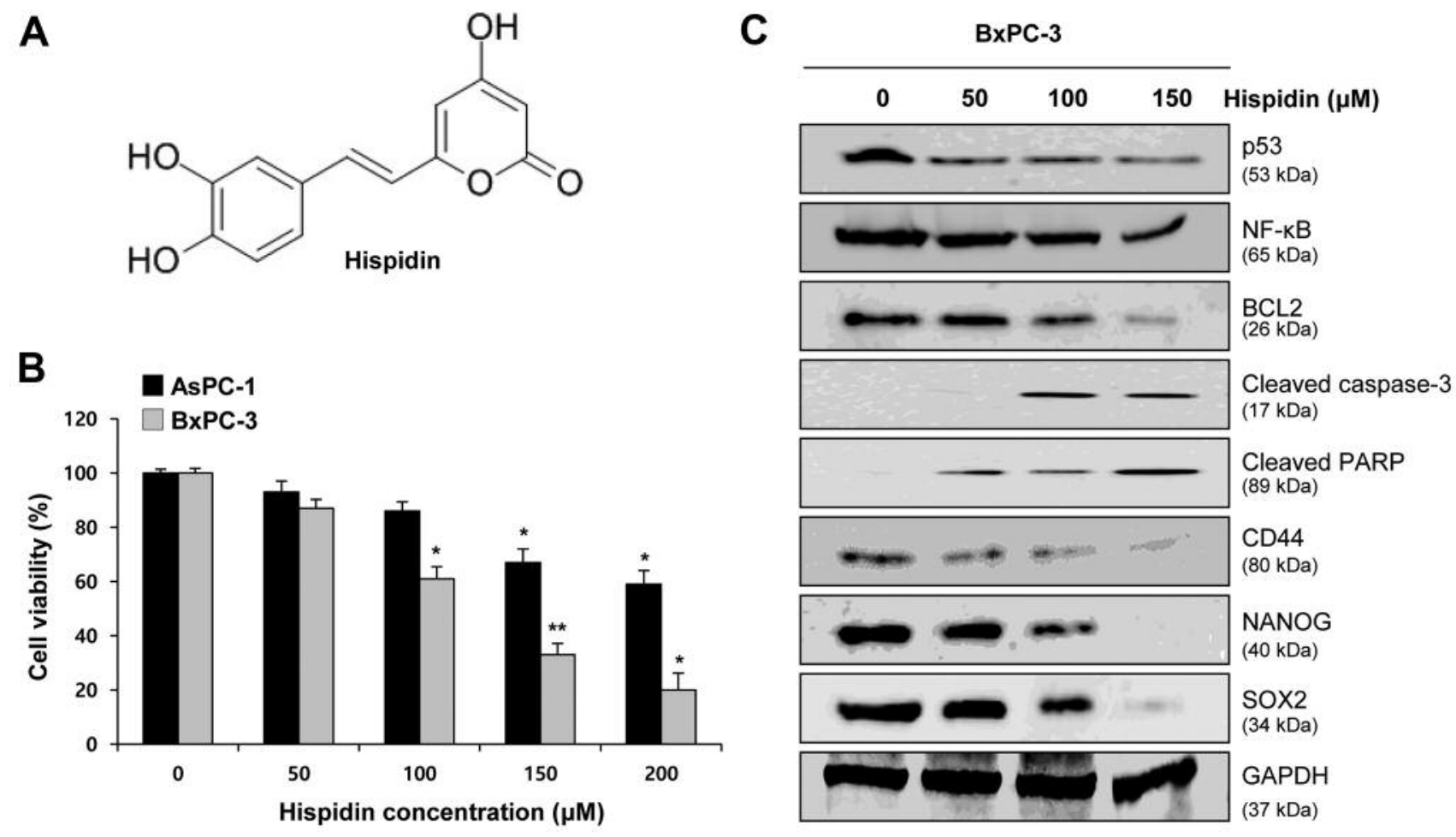

Figure 1. Effect of hispidin on pancreatic cancer cell proliferation and stemness. A: Two-dimensional structure of hispidin. B: 3-(4,5-Dimethylthiazol2-yl)-2,5-diphenyltetrazolium bromide assay revealed a dose-dependent reduction of viability of hispidin-treated AsPC-1 and BxPC-3 pancreatic cancer cells. C: Western blotting showed dose-dependent effects of hispidin on tumor-suppressor p53; apoptosis-related proteins B-cell lymphoma 2 (BCL2), cleaved caspase-3, and cleaved poly (ADP-ribose) polymerase (PARP); cancer stem cell marker CD44; and stemness markers NANOG and Sex-determining region Y-box 2 (SOX2) in BxPC-3 cells. Data represent the mean $\pm S E M(n=5$ per group). Significantly different from untreated cells at *p<0.05, and ${ }^{* *} p<0.01$. NFkB: nuclear factor-kappa B; GAPDH: glyceraldehyde 3-phosphate dehydrogenase.

indicated that hispidin reduced the populations of migrating and invading CD44+ $\mathrm{BxPC}-3$ cells (Figure $3 \mathrm{~B}$ ).

The results of immunocytochemistry assays showed that hispidin reduced the stemness of $\mathrm{CD} 44^{+}$BxPC-3 cells by lowering the expression levels of stemness markers NANOG and SOX2 and the pancreatic CSC marker CD44 in cells treated with hispidin $(150 \mu \mathrm{M})$ for $48 \mathrm{~h}$ compared to the corresponding levels in untreated cells (Figure 3C and D). A western blot assay further showed that reduction of stemness was depended on hispidin concentration (Figure 3E). In the sphere-formation assay and sphere immunocytochemistry assay, treatment with $150 \mu \mathrm{M}$ hispidin for $48 \mathrm{~h}$ significantly reduced the size, number, and CD44, NANOG and SOX2 expression of spheres, indicating the reduction of self-renewal ability (Figure 3F and G). Taken together, these findings show that hispidin negatively regulates stemness of pancreatic CSCs.

Hispidin potentiates the therapeutic efficacy of gemcitabine in pancreatic CSCs by inhibiting stemness. Inhibition of the stemness in pancreatic cancer stem cells was reported to enhance the efficacy of gemcitabine-based chemotherapy (18). In our study, stemness of pancreatic CSCs was reduced by hispidin treatment. Therefore, we investigated whether hispidin synergizes the effects of gemcitabine thereby increasing the therapeutic efficacy of gemcitabine against pancreatic CSCs.

An MTT assay revealed a significant reduction in cell viability by gemcitabine when used in combination with hispidin compared to that when either treatment was used singly (Figure 4A and B). All treatments were conducted for $48 \mathrm{~h}$. To further study the mechanisms underlying the chemosensitizing effect of hispidin on gemcitabine, the expression of NF-kB, apoptosis-related proteins, stemness markers, and the pancreatic CSC marker CD44 was determined by western blotting. As shown in Figure 4C, the expression of stemness markers NANOG and SOX2, the CSC marker CD44, BCL2, and NF-kB was significantly suppressed and the expression of cleaved caspase-3 was up-regulated by combination treatment with gemcitabine and hispidin. Reduced expression of stemness markers and CD44 was confirmed in the immunocytochemistry assay (Figure 4D and 4E). 

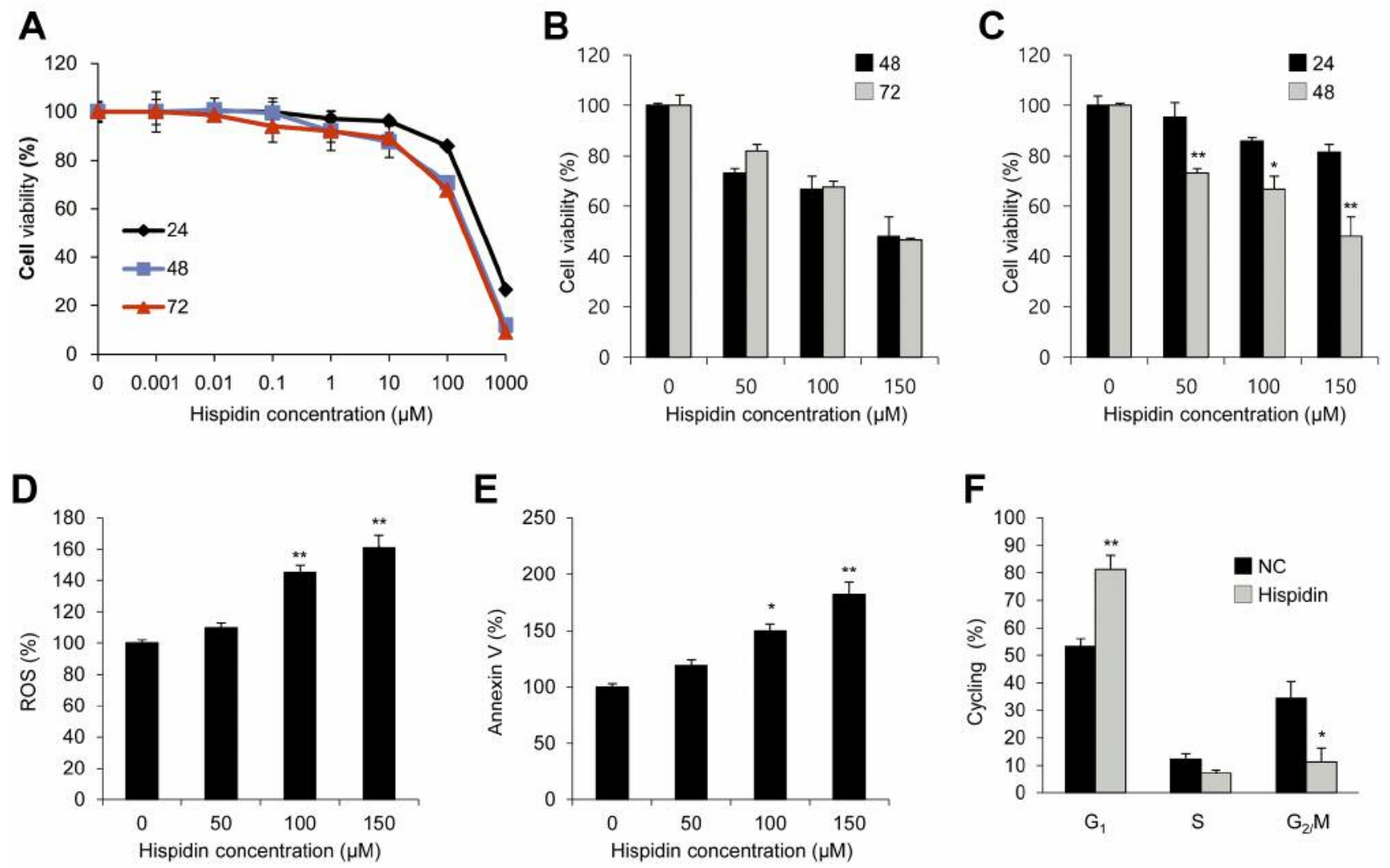

Figure 2. Hispidin induces cell apoptosis and reduces the viability of pancreatic cancer stem cells (CSCs). A: 3-(4,5-Dimethylthiazol-2-yl)-2,5diphenyltetrazolium bromide assay showed dose-dependent $(0-1000 \mu M)$ reduction in the viability of hispidin-treated CD44+ BxPC-3 cells. The reduction in viability in response to the treatment at $48 \mathrm{~h}$ was greater than that at $24 \mathrm{~h}$ but was similar to that at $72 \mathrm{~h} . \mathrm{B}, \mathrm{C}$ : Cell viability in response to dose-dependent hispidin treatment for 24, 48, and 72 h.D:2,7-Dichloro-dihydro-fluorescein diacetate (DCF-DA) assay demonstrated that hispidin increased reactive oxygen species (ROS). E: Hispidin-induced apoptosis as shown by fluorescence-activated cell sorting analysis with annexin V staining. F: Cell-cycle arrest shown by cell-cycle distribution study. Data represent the mean \pm SEM ( $n=5$ per group). Significantly different from untreated cells at $* p<0.05$, and $* * p<0.01$.

These results showed the enhanced therapeutic effects of the combination treatment compared to that when either treatment was used singly. Taken together, these in vitro results showed that hispidin exerted cytotoxic effects and synergistically enhanced the therapeutic efficacy of gemcitabine by increasing the chemosensitivity of pancreatic CSCs through abrogation of stemness.

\section{Discussion}

In this study, we describe the cytotoxic activity of a natural phenolic compound, hispidin, extracted mainly from the medicinal mushroom $P$. linteus. Hispidin may be beneficial for patients with pancreatic cancer when used as a combination therapy with gemcitabine. An in vitro analysis of cellular mechanisms suggested that hispidin increased the sensitivity of pancreatic CSCs to gemcitabine via inhibiting stemness.
$\mathrm{NF}-\mathrm{kB}$ is a crucial transcription factor that is expressed ubiquitously in pancreatic cancer cells. It is involved in cellular functions such as cell-cycle control, stress adaptation, inflammation, and apoptosis. It also induces tumorigenesis, invasion, metastasis, and resistance to anticancer therapies and plays a major role in oncogenesis $(19,20)$. It has been reported that inhibition of NF-kB, which induces resistance of pancreatic cancer cells to anticancer agents such as gemcitabine and paclitaxel (21), enhances the antitumor effects of chemotherapy $(12,22)$. Moreover, the down-regulation of stemness genes such as $N A N O G$ and $S O X 2$ is also involved in the inhibition of tumorigenicity, metastasis and chemoresistance (23). In the present study, we showed that hispidin exerts cytotoxic effects against BxPC3 and AsPC-1 pancreatic cancer cell lines by inhibiting stemness and NF-kB. The results indicated that hispidin induced $\mathrm{BxPC}-3$ cell apoptosis, thereby reducing cell 
A

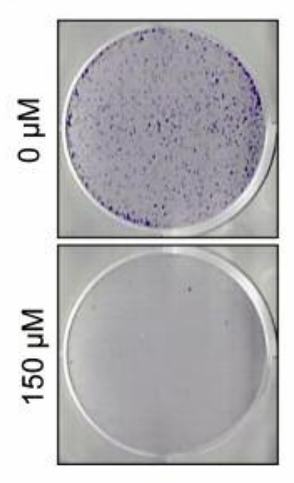

D

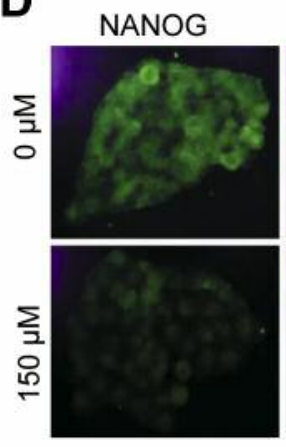

B

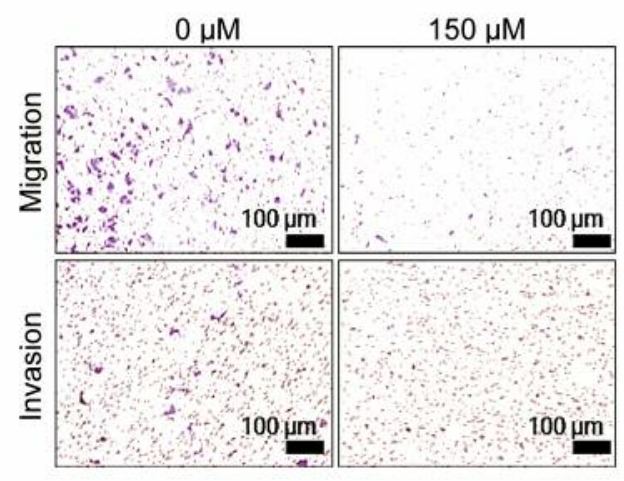

SOX2

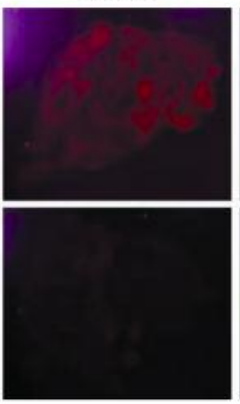

DAPI

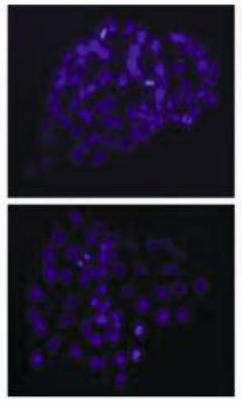

MERGE

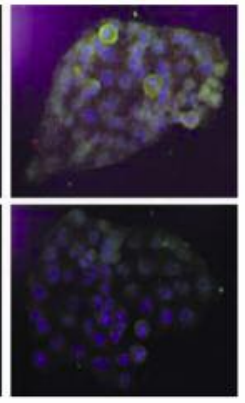

C
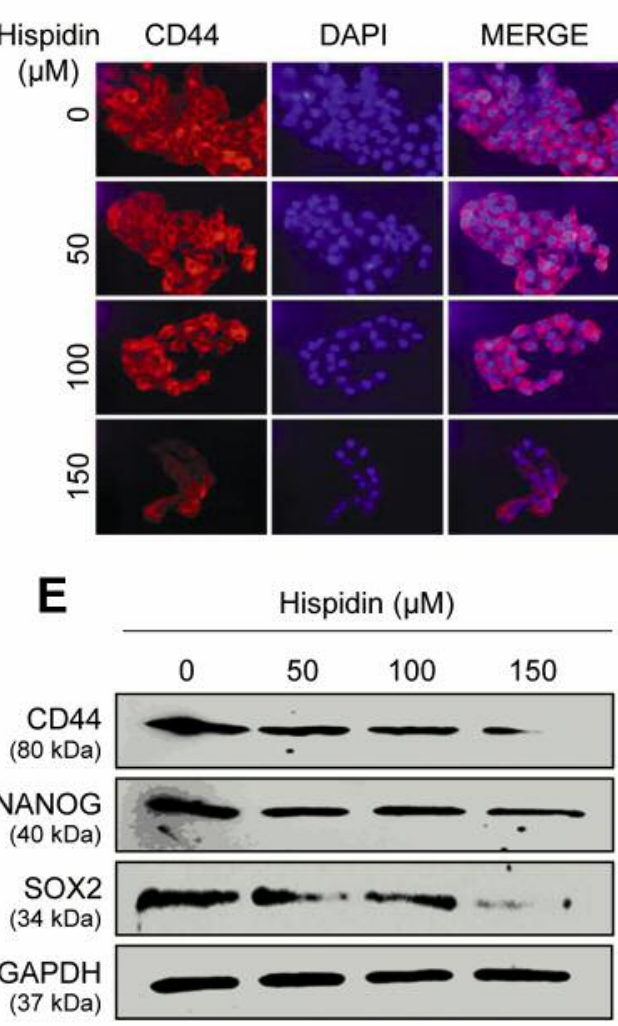

$\mathbf{F}$

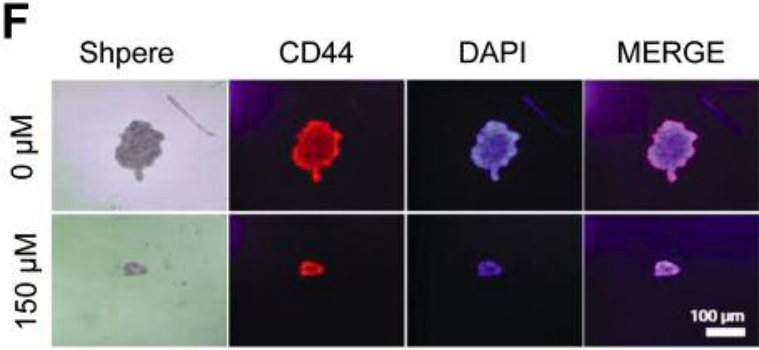

G

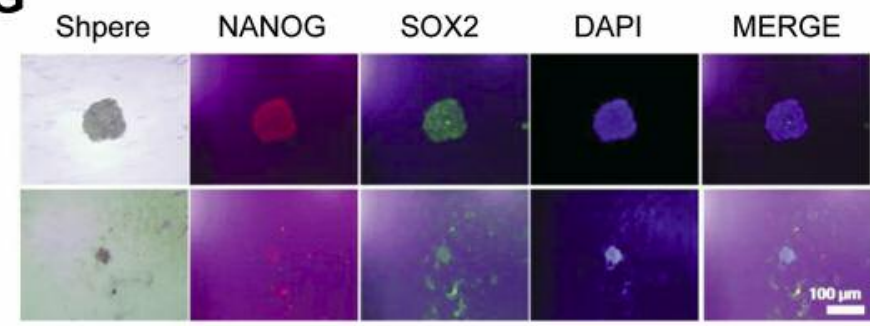

Figure 3. Inhibition of pancreatic cancer stem-like properties by hispidin treatment. A: Colony-formation assay showing the effect of $150 \mu M$ hispidin on BxPC-3 cancer stem cell (CSC) proliferation. B: Effect of hispidin on cell mobility was assessed by transwell migration and invasion assays. C, D: Immunocytochemistry assay showed $150 \mu \mathrm{M}$ hispidin suppressed the stemness of CD44+ BxPC-3 CSCs in a dose-dependent manner through reduction of expression of stemness markers. E: Western blotting confirming findings shown in $C$ and D. F, G: Sphere-forming assay and sphere immunocytochemistry assay revealed that hispidin reduced the self-renewal ability of pancreatic CSCs. Data represent the mean $\pm S E M$ ( $n=5$ per group). SOX2: Sex-determining region Y-box 2; GAPDH: glyceraldehyde 3-phosphate dehydrogenase; DAPI: 4',6-diamidino-2-phenylindole staining .

proliferation and cancer stemness. NF-kB plays a significant role in regulating the pancreatic CSC population, which was recently identified as candidate minor cell population responsible for resistance to chemotherapy and radiation therapy (24). Pancreatic CSCs are generally identified as $\mathrm{CD} 44^{+} / \mathrm{CD} 24^{+} /$epithelial-specific antigen $\left(\mathrm{ESA}^{+}\right)$cells. These antigens determine the characteristics of CSCs. Stemness of $\mathrm{CD}_{4} 4^{+}$pancreatic CSCs is involved in the resistance to chemotherapy and radiation therapy. Moreover,
CD44 has been indicated as a marker of poor prognosis of pancreatic cancer (25-28). Interestingly, we found that hispidin inhibited stemness markers and NF-kB in BxPC-3 $\mathrm{CD} 44^{+}$cells. We also observed that hispidin had the ability to inhibit BxPC-3 CSC proliferation by inducing apoptosis and cell-cycle arrest, thereby indicating the effects of hispidin against pancreatic CSCs. Further in vitro assays showed that hispidin diminished colony-forming ability, selfrenewal ability and metastasis of pancreatic CSCs. 

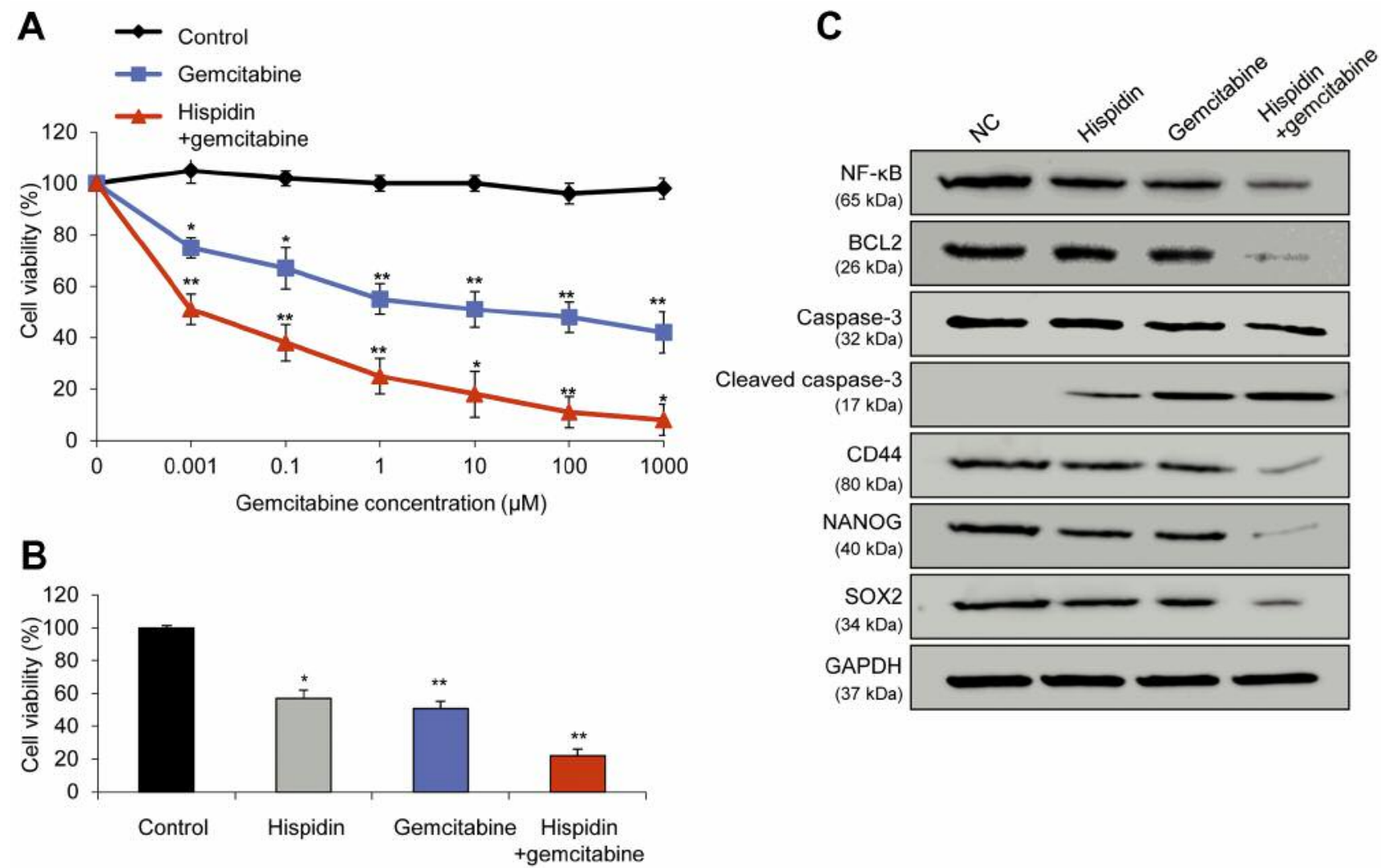

D

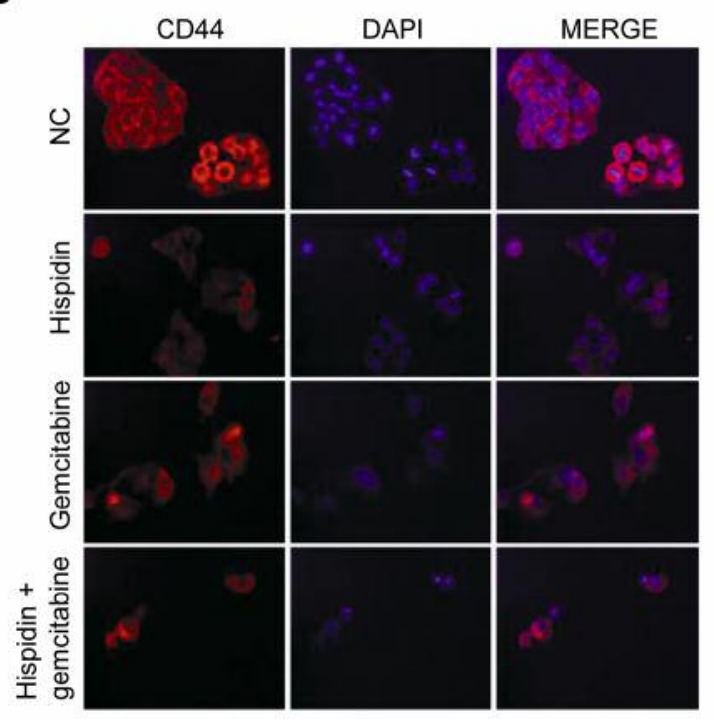

$\mathbf{E}$
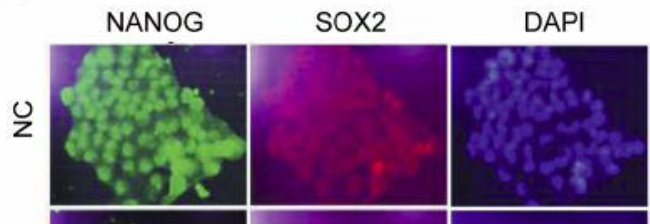

MERGE
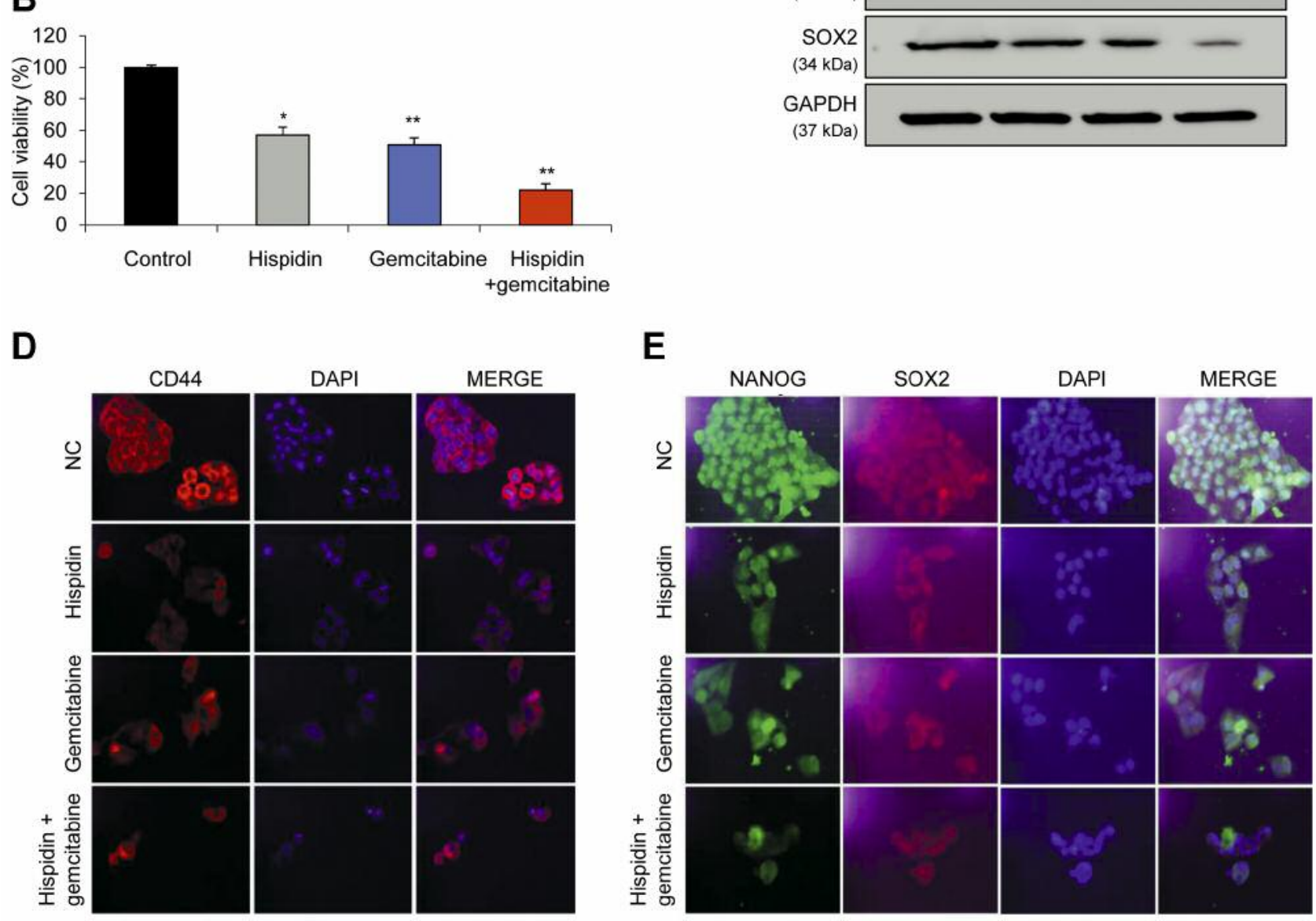

Figure 4. Hispidin enhances the sensitivity of $\mathrm{CD} 44^{+} \mathrm{BxPC}-3$ stem cells to gemcitabine by inhibiting stemness. A: Viability of cells treated with the combination of hispidin and gemcitabine was significantly reduced in a dose-dependent manner compared to cells subjected to either treatment alone. B: Cell viability of $\mathrm{CD}_{4} 4^{+} \mathrm{BxPC}-3 \mathrm{CSCs}$. The concentrations of hispidin and gemcitabine used were $150 \mu \mathrm{M}$ and $1 \mu \mathrm{M}$, respectively; the combination therapy of hispidin and gemcitabine was performed for $48 \mathrm{~h}$. C: Western blotting showed significantly reduced expression of stemness markers, the CD44 stem cell marker, and apoptosis-related proteins by synergistic treatment. Immunocytochemistry assays confirmed a greater reduction in D: CD44 and E: NANOG and Sex-determining region Y-box 2 (SOX2) expression after the combination treatment than that after either treatment alone. Data represent the mean $\pm S E M(n=5$ per group). Significantly different from untreated cells at $* p<0.05$, and $* * p<0.01$. NFKB: nuclear factor-kappa B; BCL2: B-cell lymphoma 2; GAPDH: glyceraldehyde 3-phosphate dehydrogenase; DAPI: 4',6-diamidino-2phenylindole staining. 
NF-kB plays a critical role in the development and progression of chemoresistance to existing drugs for pancreatic cancer, including gemcitabine, a standard chemotherapeutic agent. Accumulating evidence strongly suggests that agents that can block NF-kB may reduce chemoresistance to gemcitabine and may serve as novel synergistic therapeutic regimens in combination with gemcitabine for pancreatic cancer (29-31). Furthermore, natural products can play an important role as chemosensitizers in the down-regulation of stemness, thereby inhibiting the chemoresistance of pancreatic cancer cells to existing drugs $(22,32)$. Similarly, our results showed that hispidin acts as a chemosensitizer of gemcitabine by downregulating NF-kB expression and stemness synergistically with gemcitabine.

Taken together, the results of this study indicate that hispidin has the potential to exert cytotoxic effects against pancreatic CSCs alone and synergize therapeutic efficacy of gemcitabine by inhibiting stemness when used in combination. Although this was an in vitro study, the results provide evidence for the need to conduct more in-depth investigations to understand the mechanisms associated with combined effects of gemcitabine and hispidin, especially with regard to effects on stemness.

\section{Conflicts of Interest}

The Authors declare no conflict of interest in regard to this study.

\section{Acknowledgements}

The Authors gratefully acknowledge screening of natural products for drug discovery support from 2017 Research and Education (R\&E), Jeju Science High School (Students: Seok Won Jeong, Da Hyun Kang, Tae Woo Lee, Ji Min Han and schoolteacher: Woo Yong Jin), Jeju, Republic of Korea. This research was supported by Basic Science Research Program through the National Research Foundation of Korea (NRF) funded by the Ministry of Education (2016R1A6A1A03012862)

\section{References}

1 Siegel RL, Miller KD and Jemal A: Cancer statistics, 2015. CA Cancer J Clin 65(1): 5-29, 2015.

2 Zhu S, Zhou H-Y, Deng S-C, Deng S-J, He C, Li X, Chen J-Y, Jin Y, Hu Z-L, Wang F, Wang C-Y and Zhao G: ASIC1 and ASIC3 contribute to acidity-induced emt of pancreatic cancer through activating $\mathrm{CA}(2+) / \mathrm{RHOA}$ pathway. Cell Death Dis $8(5)$ : e2806, 2017.

3 Li J, Wu H, Li W, Yin L, Guo S, Xu X, Ouyang Y, Zhao Z, Liu S, Tian Y, Tian Z, Ju J, Ni B and Wang H: Down-regulated mir-506 expression facilitates pancreatic cancer progression and chemoresistance via SPHK1/AKT/NF-KB signaling. Oncogene 35(42): 5501-5514, 2016.

4 Bardeesy N and DePinho RA: Pancreatic cancer biology and genetics. Nature Rev Cancer 2: 897, 2002.
5 Kobayashi N, Okazaki S, Sampetrean O, Irie J, Itoh H and Saya $\mathrm{H}$ : CD44 variant inhibits insulin secretion in pancreatic $\beta$ cells by attenuating LAT1-mediated amino acid uptake. Sci Rep 8(1): 2785, 2018.

6 Matsubara S, Ding Q, Miyazaki Y, Kuwahata T, Tsukasa K and Takao S: Mtor plays critical roles in pancreatic cancer stem cells through specific and stemness-related functions. Sci Rep 3: 3230, 2013.

7 Kumazoe M, Takai M, Hiroi S, Takeuchi C, Yamanouchi M, Nojiri T, Onda H, Bae J, Huang Y, Takamatsu K, Yamashita S, Yamada S, Kangawa K, Takahashi T, Tanaka H and Tachibana H: PDE3 inhibitor and EGCG combination treatment suppress cancer stem cell properties in pancreatic ductal adenocarcinoma. Sci Rep 7: 1917, 2017.

8 Schniewind B, Christgen M, Kurdow R, Haye S, Kremer B, Kalthoff $\mathrm{H}$ and Ungefroren $\mathrm{H}$ : Resistance of pancreatic cancer to gemcitabine treatment is dependent on mitochondria-mediated apoptosis. Int J Cancer 109(2): 182-188, 2004.

9 Duan Q, Zhao H, Zhang Z, Li H, Wu H, Shen Q, Wang C and Yin T: Mechanistic evaluation and translational signature of gemcitabine-induced chemoresistance by quantitative phosphoproteomics analysis with ITRAQ labeling mass spectrometry. Sci Rep 7: 12891, 2017.

10 Lee HS, Park SB, Kim SA, Kwon SK, Cha H, Lee DY, Ro S, Cho JM and Song SY: A novel hdac inhibitor, cg200745, inhibits pancreatic cancer cell growth and overcomes gemcitabine resistance. Sci Rep 7: 41615, 2017.

11 Wang $\mathrm{Y}, \mathrm{Wu} \mathrm{X}$, Zhou $\mathrm{Y}$, Jiang $\mathrm{H}$, Pan $\mathrm{S}$ and Sun B: Piperlongumine suppresses growth and sensitizes pancreatic tumors to gemcitabine in a xenograft mouse model by modulating the NF-kappa B pathway. Cancer Prev Res 9(3): 234, 2016.

12 Qanungo S, Uys JD, Manevich Y, Distler AM, Shaner B, Hill EG, Mieyal JJ, Lemasters JJ, Townsend DM and Nieminen A-L: $N$ Acetyl-L-cysteine sensitizes pancreatic cancers to gemcitabine by targeting the NFkB pathway. Biomed Pharmacother 68(7): 855$864,2014$.

13 Lv LX, Zhou ZX, Zhou Z, Zhang LJ, Yan R, Zhao Z, Yang LY, Bian XY, Jiang HY, Li YD, Sun YS, Xu QQ, Hu GL, Guan WJ and Li YQ: Hispidin induces autophagic and necrotic death in sgc-7901 gastric cancer cells through lysosomal membrane permeabilization by inhibiting tubulin polymerization. Oncotarget 8(16): 26992-27006, 2017.

14 Jang JS, Lee JS, Lee JH, Kwon DS, Lee KE, Lee SY and Hong EK: Hispidin produced from phellinus linteus protects pancreatic $\beta$-cells from damage by hydrogen peroxide. Arch Pharmacol Res 33(6): 853-861, 2010.

15 Park MJ, Lee SJ, Song EJ, Sim CY, Ha S-J and Hong KE: Cytoprotective effect of hispidin against palmitate-induced lipotoxicity in c2c12 myotubes. Molecules 20(4): 5456-5467, 2015.

16 Gonindard C, Bergonzi C, Denier C, Sergheraert C, Klaebe A, Chavant L and Hollande E: Synthetic hispidin, a PKC inhibitor, is more cytotoxic toward cancer cells than normal cells in vitro. Cell Biol Toxicol 13(3): 141-153, 1997.

17 Lim JH, Lee YM, Park SR, Kim DH and Lim BO: Anticancer activity of hispidin via reactive oxygen species-mediated apoptosis in colon cancer cells. Anticancer Res 34(8): 4087-4093, 2014.

18 Zhao H, Duan Q, Zhang Z, Li H, Wu H, Shen Q, Wang C and Yin T: Up-regulation of glycolysis promotes the stemness and EMT phenotypes in gemcitabine-resistant pancreatic cancer cells. J Cell Mol Med 21(9): 2055-2067, 2017. 
19 Arlt A, Gehrz A, Müerköster S, Vorndamm J, Kruse M-L, Fölsch UR and Schäfer H: Role of NF-kB and AKT/PI3K in the resistance of pancreatic carcinoma cell lines against gemcitabine-induced cell death. Oncogene 22: 3243, 2003.

20 Xie C, Liu D, Chen Q, Yang C, Wang B and Wu H: Soluble B7$\mathrm{H} 3$ promotes the invasion and metastasis of pancreatic carcinoma cells through the TLR4/NF-kB pathway. Sci Rep 6: 27528, 2016.

21 Fujioka S, Son K, Onda S, Schmidt C, Scrabas GM, Okamoto T, Fujita T, Chiao PJ and Yanaga K: Desensitization of nfkappab for overcoming chemoresistance of pancreatic cancer cells to TNFalpha or paclitaxel. Anticancer Res 32(11): 4813-4821, 2012.

22 Gong J, Muñoz AR, Pingali S, Payton-Stewart F, Chan DE, Freeman JW, Ghosh R and Kumar AP: Down-regulation of STAT3/NF-kB potentiates gemcitabine activity in pancreatic cancer cells. Mol Carcinog 56(2): 402-411, 2017.

23 Ali MS, Gill KS, Saglio G, Cilloni D, Soden DM and Forde PF: Expressional changes in stemness markers post electrochemotherapy in pancreatic cancer cells. Bioelectrochemistry 122: 8492, 2018.

24 Sun L, Mathews LA, Cabarcas SM, Zhang X, Yang A, Zhang Y, Young MR, Klarmann KD, Keller JR and Farrar WL: Epigenetic regulation of SOX 9 by the $\mathrm{nf}-\mathrm{kb}$ signaling pathway in pancreatic cancer stem cells. Stem Cells 31(8): 1454-1466, 2013.

25 Skoda J, Hermanova M, Loja T, Nemec P, Neradil J, Karasek P and Veselska R: Co-expression of cancer stem cell markers corresponds to a pro-tumorigenic expression profile in pancreatic adenocarcinoma. PLoS ONE 11(7): e0159255, 2016.
26 Li X-P, Zhang X-W, Zheng L-Z and Guo W-J: Expression of CD44 in pancreatic cancer and its significance. Int J Clin Exp Pathol 8(6): 6724-6731, 2015.

27 Li C, Heidt DG, Dalerba P, Burant CF, Zhang L, Adsay V, Wicha M, Clarke MF and Simeone DM: Identification of pancreatic cancer stem cells. Cancer Research 67(3): 1030, 2007.

28 Jiang W, Zhang Y, Kane KT, Collins MA, Simeone DM, di Magliano MP and Nguyen KT: CD44 regulates pancreatic cancer invasion through MT1-MMP. Mol Cancer Res 13(1): 9-15, 2015.

29 Perkins ND: The diverse and complex roles of NF-KB subunits in cancer. Nature Rev Cancer 12: 121, 2012.

$30 \mathrm{Li} \mathrm{F}$ and Sethi G: Targeting transcription factor NF-KB to overcome chemoresistance and radioresistance in cancer therapy. Biochim Biophys Acta 1805(2): 167-180, 2010.

31 Namba T, Kodama R, Moritomo S, Hoshino T and Mizushima T: Zidovudine, an anti-viral drug, resensitizes gemcitabine-resistant pancreatic cancer cells to gemcitabine by inhibition of the aAKTGSK3B-SNAIL pathway. Cell Death Dis 6: e1795, 2015.

32 Horiuchi T, Uwagawa T, Shirai Y, Saito N, Iwase R, Haruki K, Shiba H, Ohashi T and Yanaga K: New treatment strategy with nuclear factor- $\mathrm{kB}$ inhibitor for pancreatic cancer. J Surg Res 206(1): 1-8, 2016.

Received May 9, 2018

Revised May 31, 2018

Accepted June 4, 2018 